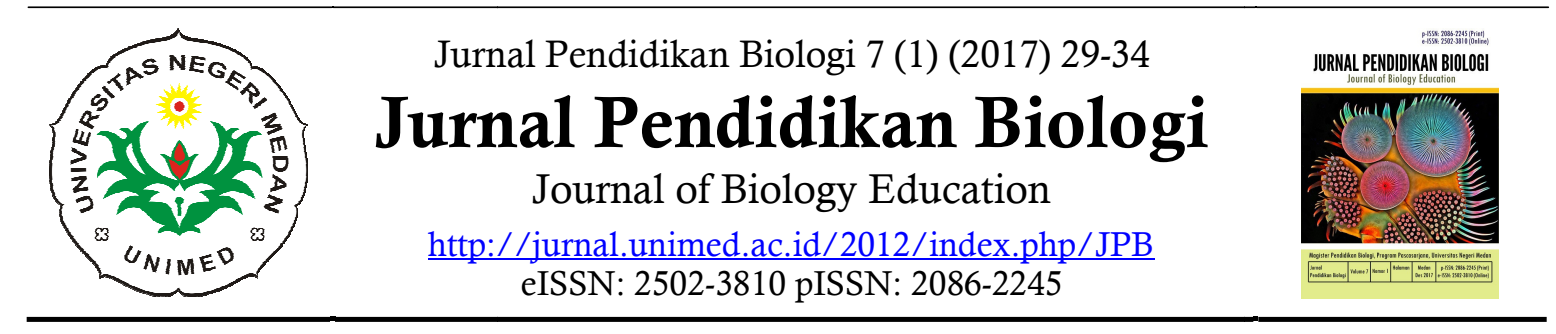

\title{
Motivasi Mahasiswa dalam Pembelajaran Biologi molekuler
}

\author{
Evi Suryanti* \\ Program Studi Pendidikan Biologi, Universitas Islam Riau, Pekanbaru, Riau, Indonesia \\ *Korespondensi: evibio@edu.uir.ac.id
}

\begin{abstract}
This research aims to explain or describe the motivation of 35 students of Pendidikan Biologi, FKIP, Universitas Islam Riau at Kota Pekanbaru in the Molecular Biology learning on Academic Year 2016/2017. The Molecular Biology learning has been done by lecture and discussion methods. Data collection was done by questionnaire technique. The questionnaire was adapted from Science Motivation Questionnaire II (SMQ-II). SMQ-II consists of five motivational components, namely intrinsic motivation, career motivation, self-determination, self-efficacy, and grade motivation with 25 statements and has 4 Likert scales, namely Strongly Agree (4), Agree (3), Less Agree (2), and Disagree (1). The result shows that $45,7 \%$ students have very good motivation and $54,3 \%$ students have good motivation. Intrinsic motivation is a more dominant motivation for students in learning Molecular Biology, followed by grade motivation, self-determination, self-efficacy and career motivation.
\end{abstract}

Keyword: learning motivation, molecular biology

\section{PENDAHULUAN}

Biologi molekuler sebagai ilmu telah berkembang sangat pesat. Perkembangannya semakin membuka banyak rahasia fenomena kehidupan. Kemajuan biologi molekuler juga berimplikasi terhadap aspek kehidupan manusia di bidang lain seperti pertanian, kesehatan, dan lingkungan. Menurut Susanto (2012), biologi molekuler memaparkan dasar-dasar molekuler setiap fenomena hayati meliputi makromolekul hayati, khususnya asam nukleat, serta proses pemeliharaan, transmisi, dan ekspresi informasi hayati yang meliputi replikasi, transkripsi, dan translasi. Yuwono (2010) memberikan pengertian biologi molekuler sebagai ilmu yang membahas tentang organisasi, aktivitas dan regulasi gen pada tingkat molekul.

Perkembangan biologi molekuler harus dapat diikuti dengan pemahaman yang baik oleh mahasiswa Pendidikan Biologi sebagai calon guru biologi, sehingga nantinya dapat membelajarkan materi Bioteknologi dengan konsep yang benar. Pemahaman terhadap Biologi molekuler yang baik dapat dicapai salah satunya jika mahasiswa memiliki motivasi belajar yang kuat. Motivasi sangat penting dalam pembelajaran. Motivasi dapat mendorong meningkatnya semangat dan ketekunan dalam belajar. Pendidik yang berhasil adalah pendidik yang mampu menumbuhkan semangat dan motivasi peserta didiknya untuk berhasil dalam pembelajaran. Menurut Anam (2015), peserta didik dengan motivasi tinggiadalah 
yang berani menunjukkan potensi kelebihannya dan menyadari keterbatasannya, serta menjadikan keterbatasan itu untuk meningkatkan kemampuannya.

Motif, atau dalam bahasa Inggris "motive", berasal dari kata movere atau motion, yang berarti gerakan atau sesuatu yang bergerak. Dalam psikologi, istilah motif diartikan sebagai gerakan yang dilakukan oleh manusia atau disebut juga perbuatan atau perilaku; juga bermakna rangsangan, dorongan, atau pembangkit tenaga bagi terjadinya suatu perbuatan (action) atau perilaku (behaviour) (Sarwono, 2013). Motivasi belajar ialah keseluruhan daya penggerak psikis di dalam diri peserta didik yang menimbulkan kegiatan belajar, menjamin kelangsungan kegiatan belajar dan memberikan arah pada kegiatan belajar itu demi mencapai suatu tujuan. Motivasi belajar memegang peranan penting dalam memberikan gairah atau semangat dalam belajar, sehingga peserta didik yang bermotivasi kuat memiliki energi banyak untuk melakukan kegiatan belajar. Motivasi belajar juga memberikan arah yang jelas dalam belajar (Winkel, 1996). Menurut Armstrong dalam Setiani dan Priansa (2015), motivasi berkaitan dengan kekuatan dan arah perilaku serta faktorfaktor yang memengaruhi seseorang untuk berperilaku dengan cara tertentu. Ada tiga komponen motivasi, yaitu: a) Arah, apa yang dicoba seseorang untuk melakukannya; b) Upaya, seberapa keras seseorang mencoba; dan c) Kegigihan, berapa lama seseorang terus mencoba. Hamalik (2001) menjelaskan fungsi motivasi sebagai pendorong timbulnya perbuatan belajar, pengarah untuk mencapai tujuan belajar yang jelas, dan penggerak untuk mempercepat tercapainya tujuan belajar.

Serangkaian faktor beragam yang memengaruhi motivasi belajar peserta didik telah diteliti, misalnya faktor-faktor internal dan eksternal seperti kinerja dan keterampilan siswa dalam proyek desain dan teknologi, orientasi tujuan dan gaya kognitif, dan faktor guru (Atkinson dalam Kwon, 2016), faktor gender (Britner, 2008), faktor gender dan usia siswa (Salta dan Koulougliotis, 2015), dan lingkungan belajar konstruktivis (Cetin-Dindar, 2016).

Penelitian ini bertujuan untuk mengetahui motivasi mahasiswa Pendidikan Biologi dalam pembelajaran Biologi molekuler. Ada lima komponen motivasi yang disurvei, yaitu intrinsic motivation (motivasi intrinsik), career motivation (motivasi karir), self-determination (keteguhan diri), self-efficacy (percaya diri), dan grade motivation (motivasi nilai).

\section{METODE}

Penelitian ini merupakan penelitian deskriptif. Menurut Setyosari (2013) tujuan penelitian deskriptif untuk menjelaskan atau mendeskripsikan suatu keadaan, peristiwa, objek, orang atau segala sesuatu yang terkait dengan variabel tertentu yang bisa dijelaskan baik dengan angka maupun kata-kata. Subyek penelitian adalah mahasiswa Pendidikan Biologi, FKIP Universitas Islam Riau yang mengambil matakuliah pilihan Biologi Molekuler pada Tahun Akademik 2016/2017 yang berjumlah 35 orang. Pembelajaran Biologi molekuler berlangsung dengan metode ceramah dan tanya-jawab.

Data dikumpulkan dengan teknik angket. Angket yang digunakan adalah angket yang diadaptasi dari Science Motivation Questionnaire II (SMQ-II) yang dikembangkan oleh Glynn, et al. (2011). Dasar diadaptasinya SMQ-II untuk penelitian ini karena SMQ-II merupakan angket yang telah terbukti reliabel, valid dan efisien (Glynn, et al., 2011). Selain itu, 
SMQ-II juga telah banyak diadaptasi oleh peneliti lain untuk studi di bidang pembelajaran fisika (Așıssoy dan Özdamlı, 2016), kimia (Salta dan Koulougliotis, 2015) dan teknologi (Kwon, 2016). Angket terdiri dari 25 pernyataan dan mempunyai 4 skala Likert, yaitu Sangat Setuju (4), Setuju (3), Kurang Setuju (2), dan Tidak Setuju (1). Total skor motivasi mahasiswa dikelompokkan menurut kategori berikut:

Tabel 1. Interval Skor dan Kategori Motivasi

\begin{tabular}{ccc}
\hline No. & Interval skor & Kategori \\
\hline 1 & $25-43$ & Motivasi Kurang Baik \\
2 & $44-62$ & Motivasi Cukup Baik \\
3 & $63-81$ & Motivasi Baik \\
4 & $82-100$ & Motivasi Sangat Baik \\
\hline
\end{tabular}

\section{HASIL}

Bagian ini akan memaparkan profil motivasi mahasiswa dan jenis motivasi yang lebih dominan dalam pembelajaran Biologi molekuler.

\section{Kategori Motivasi Mahasiswa}

Motivasi belajar sangat penting bagi seorang peserta didik. Peserta didik dengan motivasi yang baik biasanya akan memperoleh hasil belajar yang baik pula. Hasil analisis data menunjukkan bahwa 45,7\% mahasiswa motivasinya sangat baik dan $54,3 \%$ mahasiswa memiliki motivasi yang baik. Tidak seorangpun mahasiswa yang memiliki motivasi kurang baik dan cukup baik. Kategori motivasi mahasiswa dalam pembelajaran Biologi molekuler dapat dilihat pada Tabel 2 berikut:

Tabel 2. Profil Kategori Motivasi Mahasiswa

\begin{tabular}{cccc}
\hline No. & Interval Skor & Kategori & Jumlah Mahasiswa $=\mathbf{~ N ~ ( \% ) ~}$ \\
\hline 1 & $25-43$ & Motivasi Kurang Baik & 0 \\
2 & $44-62$ & Motivasi Cukup Baik & 0 \\
3 & $63-81$ & Motivasi Baik & 19 orang (54,3) \\
4 & $82-100$ & Motivasi Sangat Baik & 16 orang (45,7) \\
\hline \multicolumn{5}{c}{ Total } & 35 orang \\
\hline
\end{tabular}

$\begin{array}{ll}\begin{array}{l}\text { Motivasi Mahasiswa pada Setiap } \\ \text { Komponen }\end{array} & \begin{array}{l}\text { self-determination (keteguhan diri), self- } \\ \text { efficacy (percaya diri), dan grade motivation } \\ \text { (motivasi nilai). Rerata motivasi }\end{array} \\ \text { SMQ-II terdiri dari lima komponen } & \begin{array}{l}\text { mahasiswa pada setiap komponen motivasi } \\ \text { dapat dilihat pada grafik berikut: }\end{array}\end{array}$




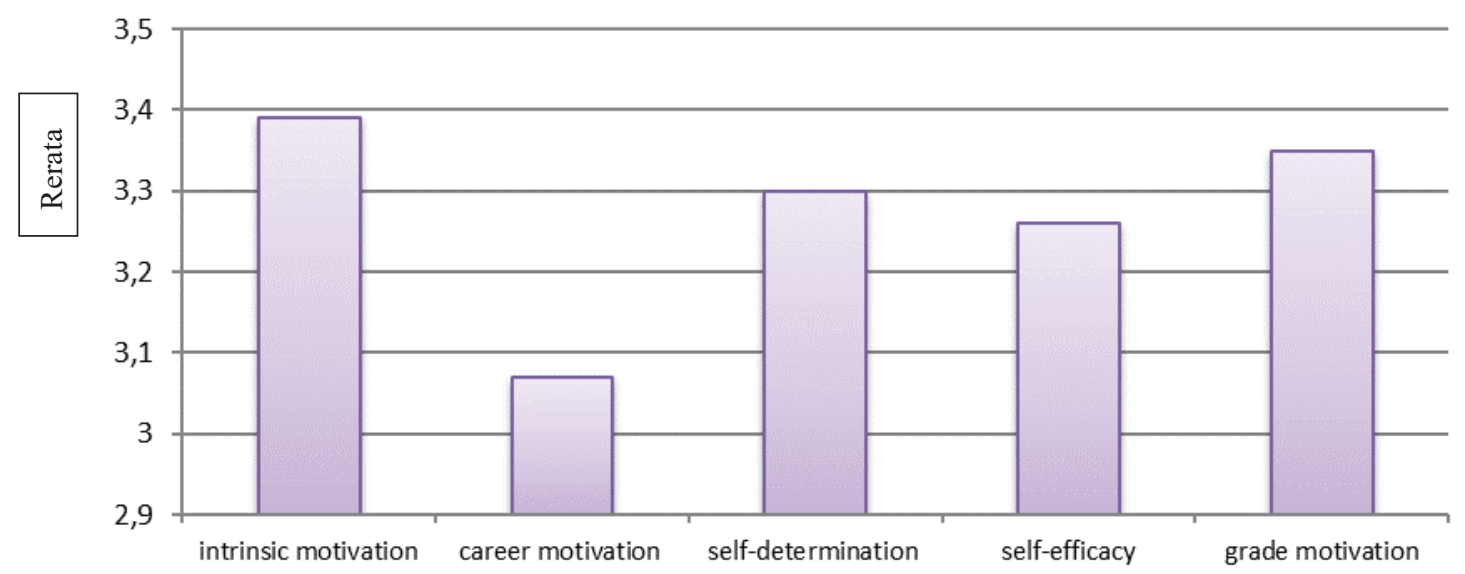

Gambar 1. Rerata skor motivasi pada setiap komponen

\section{PEMBAHASAN}

Data pada Tabel 2 menunjukkan bahwa tingkat motivasi mahasiswa dalam pembelajaran Biologi molekuler adalah tinggi. Motivasi yang tinggi ini dapat menjadi salah satu modal untuk berhasil dalam pembelajaran Biologi molekuler, karena motivasi yang tinggi menjadi energi yang besar untuk melakukan usaha dalam mencapai keberhasilan belajar. Seperti yang dijelaskan oleh Winkel (1996) bahwa peserta didik yang bermotivasi kuat memiliki energi yang banyak untuk melakukan kegiatan belajar dan memiliki arah yang jelas dalam belajar.

Berdasarkan grafik pada Gambar 1 terlihat bahwa intrinsic motivation merupakan motivasi yang lebih dominan bagi mahasiswa dalam pembelajaran Biologi molekuler, diikuti oleh grade motivation, self-determination, self-efficacy dan career motivation. Komponen career motivation adalah yang paling tidak dominan. Dominannya intrinsic motivation ini memperkuat dugaan bahwa prestasi mahasiswa dalam pembelajaran Biologi molekuler adalah baik.

Selanjutnya, berdasarkan grafik di atas peneliti berpendapat bahwa jika intrinsic motivation merupakan motivasi yang lebih dominan, maka seharusnya self- determination (keteguhan diri) dan selfefficacy (percaya diri) juga lebih dominan karena keduanya juga merupakan motivasi intrinsik. Namun, temuan penelitian menunjukkan bahwa grade motivation (motivasi nilai) yang lebih besar daripada self-determination (keteguhan diri) dan selfefficacy (percaya diri). Grade motivation (motivasi nilai) merupakan motivasi ekstrinsik, yaitu dorongan belajar yang diperoleh peserta didik dari luar dirinya. Berdasarkan temuan ini terlihat bahwa mahasiswa juga memerlukan motivasi ekstrinsik untuk memperkuat motivasi intrinsiknya dalam pembelajaran Biologi molekuler. Di antara dua komponen motivasi ekstrinsik yang disurvei, maka grade motivation (motivasi nilai) lebih dominan daripada career motivation (motivasi karir). Temuan ini didukung oleh Reid (2009) bahwa idealnya motivasi haruslah intrinsik, di mana pembelajar memiliki motivasi diri (self-motivating), namun motivasi ekstrinsik juga diperlukan untuk kesuksesan pembelajaran. Selanjutnya Reid berpendapat bahwa motivasi intrinsik dan ekstrinsik perlu dipertimbangkan dalam merencanakan pembelajaran, karena tidak semua pembelajar secara intuitif dan intrinsik termotivasi untuk belajar. Contoh motivasi ekstrinsik adalah pemberian tugas, adanya 
penghargaan, pengaruh dari kelompok teman sebaya, adanya umpan balik positif dalam belajar, dan pencapaian prestasi.

Schunk, et al. (2012) menjelaskan bahwa pembelajar yang termotivasi secara intrinsik mengerjakan tugas-tugas karena mereka mendapati bahwa tugas tersebut menyenangkan, sedangkan pembelajar yang termotivasi secara ektrinsik mengerjakan tugas karena mereka meyakini bahwa partisipasi tersebut akan menyebabkan berbagai konsekuensi yang diinginkan, seperti mendapatkan hadiah, menerima pujian dari guru, atau terhindar dari hukuman. Lepper dan Hodell dalam Schunk, et al. (2012) mengidentifikasi empat sumber utama motivasi intrinsik, yaitu: tantangan, keingintahuan, kontrol, dan fantasi.

Penelitian ini mempunyai keterbatasan yaitu tidak dilakukannya wawancara terhadap mahasiswa, sehingga temuan yang diperoleh dari angket tidak bisa dianalisis lebih rinci. Namun, temuan penelitian ini mendukung upaya untuk mengoptimalkan kualitas pembelajaran Biologi molekuler agar motivasi belajar mahasiswa dapat ditingkatkan lebih baik lagi. Motivasi belajar yang baik akan dapat menghasilkan prestasi belajar yang juga baik. Optimalisasi kualitas pembelajaran Biologi molekuler dapat dilakukan dengan penerapan strategi pembelajaran yang dapat mengaktifkan mahasiswa, misalnya dengan strategi free inquiry, metode praktikum, atau penggunaan media pembelajaran yang menarik. Disarankan dalam pembelajaran Biologi molekuler agar menerapkan strategi free inquiry, metode praktikum, atau penggunaan media pembelajaran yang menarik dan menganalisis dampaknya terhadap motivasi belajar Biologi molekuler. Selanjutnya perlu dianalisis hubungan antara motivasi terhadap hasil belajar Biologi molekuler.

\section{KESIMPULAN}

Berdasarkan temuan penelitian dapat disimpulkan bahwa motivasi mahasiswa dalam pembelajaran Biologi molekuler berada pada kategori sangat baik dan baik. Intrinsic motivation merupakan komponen motivasi yang lebih dominan, sedangkan career motivation adalah komponen yang paling tidak dominan

\section{UCAPAN TERIMA KASIH}

Penelitian ini didukung oleh Kemenristekdikti melalui Beasiswa BPPDN.

\section{DAFTAR PUSTAKA}

Anam, K., 2015. Pembelajaran berbasis inkuiri: Metode dan aplikasi. Yogyakarta: Pustaka Pelajar.

Aşıksoy, G. and Özdamlı, F., 2016. Flipped classroom adapted to the ARCS model of motivation and applied to a physics course. Eurasia Journal of Mathematics, Science \& Technology Education, 12(6), pp. 1589-1603.

Britner, S. L., 2008. Motivation in high school science students: A comparison of gender differences in life, physical, and earth science classes. Journal of Research in Science Teaching, 45(8), pp. 955-970.

Cetin-Dindar, A., 2016. Student motivation in constructivist learning environment. Eurasia Journal of Mathematics, Science \& Technology Education, 12(2), pp. 233-247.

Glynn, S.M., Brickman, P., Armstrong, N., and Taasoobshirazi, G., 2011. Science Motivation Questionnaire II: Validation with science majors and nonscience majors. Journal of Research in Science Teaching, 48(10), pp. 1159-1176.

Hamalik, O., 2001. Proses belajar mengajar. Bandung: Bumi Aksara.

Kwon, H., 2016. Middle school students' motivation for learning technology in South Korea. Eurasia Journal of Mathematics, Science \& Technology Education, 12(4), pp. 1033-1046.

Reid, G., 2009. Memotivasi siswa di kelas: Gagasan dan strategi. (Penerjemah: Hartati Widiastuti) Jakarta: PT. Indeks.

Salta, K., and Koulougliotis, D., 2015. Assessing motivation to learn chemistry: Adaptation and 
validation of Science Motivation Questionnaire II with Greek secondary school students. Chemistry Education Research and Practice, 16, pp. 237-250.

Sarwono, S., 2013. Pengantar psikologi umum. Jakarta: Rajawali Pers.

Schunk, D.H., Pintrich, P.R., and Meece, J.L., 2012: Motivasi dalam pendidikan: Teori, penelitian, dan aplikasi. (Penerjemah: Ellys Tjo). Jakarta: PT. Indeks.

Setiani, A. dan Priansa, D.J., 2015. Manajemen peserta didik dan model pembelajaran. Bandung: Alfabeta.

Setyosari, P., 2013. Metode penelitian pendidikan \& pengembangan. Edisi ketiga. Jakarta: Kencana Prenada Media Group.

Susanto, A.H., 2012. Bahan ajar biologi molekuler. Fakultas Biologi, Universitas Jenderal Soedirman, Semarang.

Winkel, W.S., 1996. Psikologi pengajaran (edisi yang disempurnakan, cet. 4). Jakarta: Grasindo.

Yuwono, T., 2010. Biologi molekuler. Jakarta: Erlangga. 